\title{
Inhibitory Effect of Probiotic Bacteria Isolated from Camel Milk on Clinical Strains of Drug-Resistant Helicobacter pylori
}

\author{
Afsaneh Sikarchi (MSc) \\ Department of Biology, Islamic Azad \\ University, Gorgan Branch, Gorgan, \\ Iran \\ Leila Fozouni (PhD) \\ Department of Biology, Islamic Azad \\ University, Gorgan Branch, Gorgan, \\ Iran \\ Corresponding Author: Leila \\ Fozouni \\ Tel: +98-911-151-8674 \\ Email: lili_kia@yahoo.com \\ Address: Islamic Azad University, \\ Gorgan Branch, Gorgan, Iran \\ Received : 11 Sep 2017 \\ Revised: 01 Jan 2018 \\ Accepted: 16 Jan 2018 \\ Afsaneh Sikarchi 0000000152283381 \\ Leila Fozouni 0000000222480354
}

\section{ABSTRACT}

Background and Objectives: Helicobacter pylori is the most common cause of gastritis and ulcer worldwide. Treatment of such infections may lead to failure due to drug resistance. This study aimed to investigate the antimicrobial effects of bacteria present in camel milk on the growth of drug-resistant clinical isolates of H. pylori.

Methods: In this cross-sectional study, biopsy samples from 75 patients with digestive symptoms were transferred to laboratory in transport medium containing homogeneous compounds. In order to isolate H. pylori, urease-positive biopsies were promptly cultured in brucella agar enriched with defibrinated sheep blood and fetal calf serum. Disk diffusion agar test was used to evaluate antibiotic susceptibility and agar well diffusion method was applied to study the antagonistic effect of probiotics isolated from camel milk on the H. pylori isolates.

Results: The frequency of $H$. pylori isolates was $42.7 \%$. The highest rate of resistance was observed against metronidazole (56.3\%). In addition, the rate of resistant to amoxicillin, ciprofloxacin, and clarithromycin and tetracycline was 31.3\%, 18.0\%, 15.6\%, respectively. Lactobacillus plantarum (59.3\%) was more frequent than other Lactobacillus species. L. plantarum, Lactobacillus fermentum and Lactobacillus casei showed favorable inhibitory effects against the H. pylori isolates, but $L$. plantarum (with inhibition zone diameter of $20.3 \mathrm{~mm}$ ) showed the highest inhibitory effect.

Conclusion: Considering the increasing rate of drug resistance and the inhibitory effect of probiotics isolated from milk, health providers recommend that promoting consumption of probiotic food seems beneficial for the general population and those suffering from gastrointestinal disorders.

Keywords: Helicobacter pylori, Drug resistance, Camel, milk, Probiotics. 


\section{INTRODUCTION}

Today, Helicobacter pylori is one the most common cause of gastric infections and ulcers in the world, and $40-50 \%$ of humans have been affected by this bacterium. According to the World Health Organization, $H$. pylori is recognized as a type 1 carcinogen (1-3). The bacterium is abundant in the gastric mucosa of carriers and can continue its growth by penetrating into the mucin layer. It can also infect gastric mucosa for decades in spite of acquired immune responses, inflammation and the continuous alternation of gastric epithelial cells (2).

H. pylori is a curved, gram-negative, motile and non-spore-forming bacterium with 4-6 polar flagella. The bacterium grows under microaerophilic conditions. High humidity and temperature of $35-37{ }^{\circ} \mathrm{C}$ are the optimal growth conditions. Most strains require 3-5 days and sometimes 7 days of incubation (1). Since the bacteria are located under the protecting mucin layer, only antibiotics that could reach beneath the mucous membrane are effective (4). Amoxicillin, tetracycline, metronidazole and clarithromycin along with proton pump inhibitors and bismuth salts are usually used for treatment of $H$. pylori infections. However, the side effects and antibiotic resistance may sometimes lead to treatment failure.

Regarding the risk of drug resistance in various infections, it is recommended using a combination of various antimicrobial compounds to overcome this issue. Among these compounds, probiotics are clinically effective and economically justified alternatives. Besides, they lack the side effects of common antibiotics. Probiotics are live microorganisms with positive effects on microecology of the digestive system and help maintain human health (5). Beneficial role of probiotics in treatment of gastrointestinal diseases such as acute diarrhea has been confirmed (6). Probiotics exert these beneficial effects through various mechanisms such as non-immunologic mechanisms (antimicrobial substances, competing for adherence to target cells and help to reinforce the mucosal barrier), immunologic mechanisms and secretion (bacteriocins). In general, probiotics create pores in the phospholipid bilayer by affecting the cytoplasmic membrane and generating proton momentum (7). Some of the final products of lactic fermentation such as lactic acid, acetic acid and hydrogen peroxide have antibacterial effects. Production of great amounts of lactate may also have inhibitory effects on pathogenic bacteria (8).

Camel milk is a rich source of probiotics, such as lactobacilli. It has been used to treat respiratory diseases such as tuberculosis and asthma, as well as gastrointestinal and digestive disorders. In some African countries (Egypt, Sudan, Kenya and Somali), cameleers believe that drinking camel milk makes humans stronger and faster (7). Camel milk is also rich in amino acids including valine, methionine, lysine, arginine and phenylalanine. It also contains high amounts of albumin and globulin (3).

The aim of this study is to investigate the in vitro antagonistic effects of probiotics isolated from camel milk on the growth of clinical strains of $H$. pylori resistant to selective agents.

\section{MATERIAL AND METHODS}

In this cross-sectional study, we collected endoscopic specimens from 75 patients with stomach pain, duodenal ulcers, gastritis and the suspected symptoms of gastric cancer referred to two gastroenterology centers in Tehran during 2016-2017. After taking biopsy specimens from gastric antrum of each patient, the specimens were transferred to laboratory in a broth glycolate transport medium (Merck, Germany) containing homogeneous compounds. The samples were screened by initial tests such as rapid urease test and complementary tests. Urease-positive biopsy samples were cultured on brucella blood agar (Merck, Germany) containing polymyxin, vancomycin and trimethoprim, and then incubated in microaerophilic conditions $(10 \%$ $\mathrm{CO}_{2}$ ) at $37{ }^{\circ} \mathrm{C}$ for 5-6 days. The medium was enriched with $7 \%$ fetal calf serum and defibrinated sheep blood. Next, the suspected $H$. pylori colonies grown on the medium were confirmed based on morphology, Gram staining and positive urease, catalase, and oxidase reaction.

Antibiotic susceptibility testing was performed by the agar disk diffusion method (KirbyBauer method) using metronidazole $(5 \mu \mathrm{g})$, amoxicillin $(30 \mu \mathrm{g})$, ciprofloxacin $(5 \mu \mathrm{g})$, tetracycline $(10 \mu \mathrm{g})$ and clarithromycin $(2 \mu \mathrm{g})$ disks purchased from Mast Co., UK. In this test, $100 \mu \mathrm{l}$ of bacterial suspension equal to 3 
McFarland tubes was collected and cultured on Mueller Hinton agar (Merck, Germany) enriched with defibrinated sheep blood. After placing the antibiotic disks, the plate was incubated for 5 days in microaerophilic conditions. The diameter of inhibition zone around the disks was measured and recorded in millimeters according to the CLSI standards, and the results were expressed as resistant, susceptible and semi-susceptible (9). Moreover, the standard strain of $H$. pylori ATCC26695 was used as the control.

The camel milk samples were collected in sterile conditions from 3- and 7-year-old camels. The samples were transferred to laboratory in sterile containers. In order to isolate probiotic bacteria, the milk samples were inoculated into MRS broth (Merck, Germany) and M17 broth (Merck, Germany). After incubation in anaerobic conditions at 37 ${ }^{\circ} \mathrm{C}$ for 48 hours, the solutions enriched in the MRS and M17 agar were cultured and the microscopic and macroscopic properties of isolates were examined. Species were identified based on the pattern of glucose fermentation and the colonies of the isolated lactic acid bacteria were inoculated in special broth. Paraffin was added to the medium and the tube was incubated at $37^{\circ} \mathrm{C}$ for 4 days (the time required for production of antibacterial material). Later, paraffin was extracted and the contents of the tubes were transferred to sterile glass tubes. The tubes were centrifuged at 3500 RPM for 15 minutes and the supernatant was preserved for further studies.

Agar well diffusion method was used to study antimicrobial effects of probiotics. For this purpose, bacterial suspension equal to 1
McFarland standard of $H$. pylori resistant to antibiotics was prepared, and then spread on brucella blood agar (Merck, Germany). Then, wells (about $6 \mathrm{~mm}$ in diameter) were created in the medium using sterile Pasteur pipette and $100 \mathrm{ul}$ of the upper bacterial suspension isolated from milk was poured into the wells. The plates were incubated at $37{ }^{\circ} \mathrm{C}$ for 48 hours under microaerophilic conditions. Next, the diameter of inhibition zone was measured and recorded in millimeters. Each step of the tests was repeated three times. In addition, Leuconostoc mesenteroides PTCC1663 standard strain was used for comparison.

Chi-Square and paired t-test were used in SPSS (version 20) for data analysis. Statistical significance level was set at 0.05 .

Susceptibility tests were examined by error categorization.

\section{RESULTS}

H. pylori isolates were obtained from adolescents (age range: $20-59$ years, mean age: $35 \pm 8.2$ years, Male/Female: 1:1.7). Of the gastric biopsy specimens taken from patients, $32(42.7 \%)$ cases were found to be H. pylori. These cases were from patients with gastritis (75\%), peptic ulcers (19\%) and gastric cancer (6\%) (Figure1).

The H. pylori isolates were most susceptible to amoxicillin and clarithromycin and most resistant against metronidazole (Table1).

The majority (96.3\%) of lactic acid isolates belonged to Lactobacillus species. Among these, Lactobacillus plantarum was the most frequent isolate $(59.3 \%)$ and the other strains were Lactobacillus fermentum and Lactobacillus casei (Table 2).

Figure 1- Prevalence of gastrointestinal complications in patients

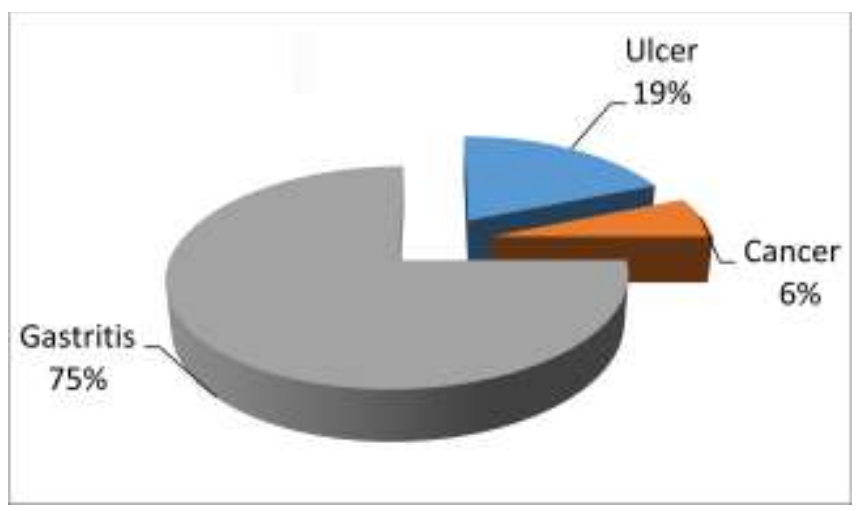


Table 1 - Frequency distribution of antibiotic resistance among $\boldsymbol{H}$. pylori isolates

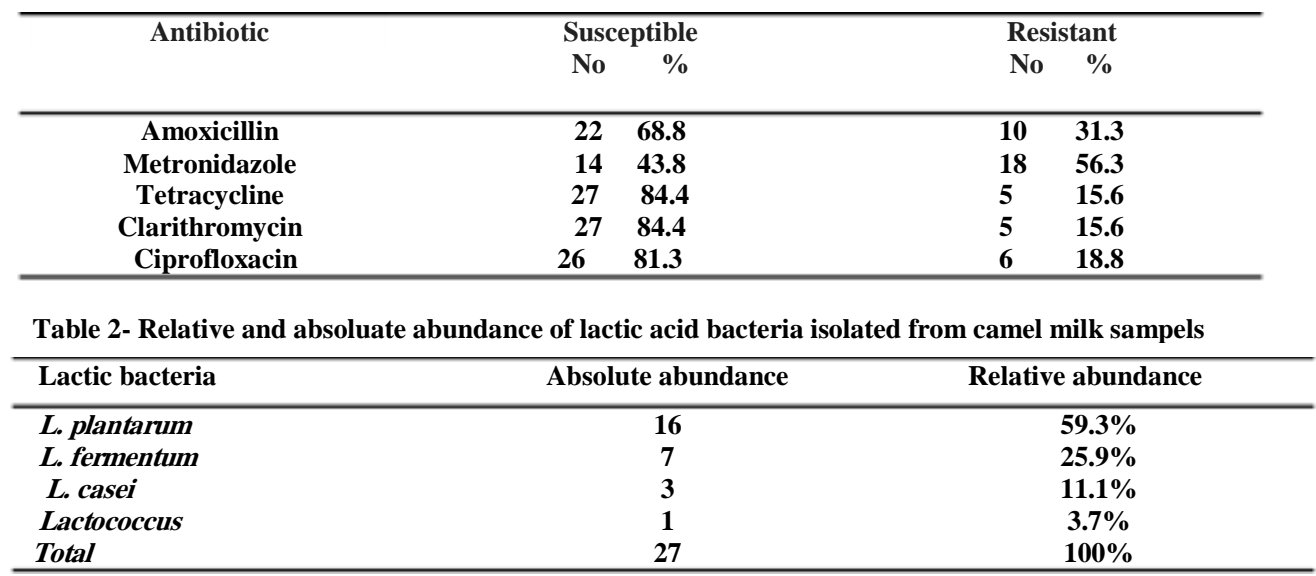

The antagonistic effect of bacteriocins generated by lactobacilli was evaluated after 35 days of incubation. Measurement of the inhibition zone indicated the complete susceptibility of drug-resistant $H$. pylori isolates to lactobacilli in laboratory conditions (Table 3).

Inhibition zone was formed upon introduction of L. plantarum, L. fermentum and L. casei to the growing antibiotic-resistant $H$. pylori. The average diameter of inhabitation zone was 21.3, 19.21 and $17.2 \mathrm{~mm}$ for $L$. plantarum, $L$. fermentum and L. casei, respectively, which confirmed the inhibitory effect of these probiotics on the resistant strains of $H$. pylori (Figure 2). However, Lactococci had not inhibitory effects on the resistant $H$. pylori strains.

Table 3- Comparison of growth and inhibition of $\mathrm{H}$. pylori strains when exposed to different probiotics

\begin{tabular}{lcccc}
\hline \multicolumn{1}{c}{ Lactobacilli } & $\begin{array}{c}\text { H. pylori } \\
3 \times 10^{8} \mathrm{cfu} / \mathrm{ml}\end{array}$ & Average & SD & Sign \\
\hline L. plantarum & Resistant & 1.17 & $\mathbf{0 . 2 0 9}$ & Not significant \\
& Sensitive & $\mathbf{1 . 2 0}$ & $\mathbf{0 . 1 6 8}$ & \\
L. fermentum & Resistant & $\mathbf{0 . 8 9}$ & $\mathbf{0 . 2 7 1}$ & Not significant \\
& Sensitive & $\mathbf{0 . 7 7}$ & $\mathbf{0 . 2 5 7}$ & \multirow{2}{*}{ Not significant } \\
L. casei & Resistant & $\mathbf{0 . 1 8 7}$ & $\mathbf{0 . 0 2 3}$ & \\
& Sensitive & $\mathbf{0 . 1 7 4}$ & $\mathbf{0 . 0 2 8}$ & \\
\hline
\end{tabular}

Figure 2- The antimicrobial effect of Lactococcus (1), L. plantarum (2), L. casei (3) and $L$. fermentum (4) on growth of $\mathrm{H}$. pylori

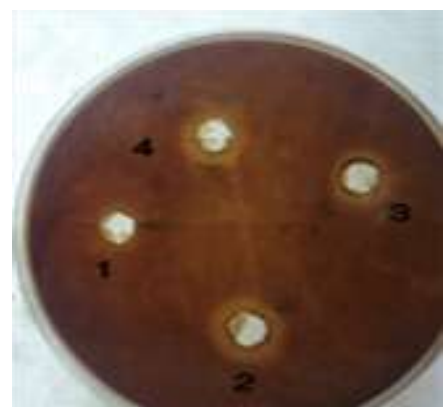

\section{DISCUSSION}

H. pylori is regarded as one of the most common causes of gastrointestinal infections worldwide. About $40-50 \%$ of the world's population is affected by this bacterium (8). $H$. pylori can also cause gastric diseases such as chronic gastritis, peptic ulcer, gastric cancer and lymphoma of mucosa-associated lymphoid tissue (10). In the present study, $42.7 \%$ of the strains were identified as $H$. pylori. This indicates the high resistance of $H$. pylori strains to most commonly used antibiotics. In our study, $18.8 \%$ of the strains were resistant to ciprofloxacin, which is less than the rates reported by studies in Germany (11), Portugal (12), France (13) and Spain (14). Given that ciprofloxacin is used as the second-line therapy for treatment of $H$. pylori, the high resistance rate observed against this antibiotic 
raises concern about the efficacy of the drug. The dissimilarities in the degree of antibiotic resistance in the mentioned studies could be due to differences in the methods used in these studies. The resistance rate of $H$. pylori to clarithromycin has been divergent in various studies. For instance, the rate of clarithromycin resistance was reported to be up to $20 \%$ in Portugal (12), Saudi Arabia (15), South Korea (16), China (17) and Iran (18), while it has been reported to be $58 \%$ in Germany (11) and $32 \%$ in Italy (19). In a study carried out by Mohammadi et al. (18) in Iran, resistance to clarithromycin was reported to be $17 \%$, which is similar to our findings. According to Selgrade and Salfringer (20), clarithromycin should be used with extra care in areas where rate of resistance is over 20\%. In Iran, Naghshvar et al. reported that all isolates were susceptible to amoxicillin (30), while a study in China stated that the rate of amoxicillin resistance was $71 \%$ (17). We found that $31.3 \%$ of the isolates were resistant to amoxicillin, which was lower than the previous reports from other countries. However, study of Falsafi reported that $42 \%$ of $\mathrm{H}$. pylori isolates were amoxicillin-resistant (21).

In the present study, $56.3 \%$ of the $H$. pylori isolates were resistant to metronidazole, which was lower than the results obtained by Mohammadi et al. (18). The rate of metronidazole resistance in Saudi Arabia (15) and China (17) was close to our study, which could be due to the regional distribution of resistance to antibiotics. The rate of resistance to tetracycline was around $15.6 \%$ in our study, while the rate of resistance to this antibiotic was no more than 5\% in Italy (19), Saudi Arabia (15) and South Korea (16). However, the rate of tetracycline resistance has been reported to be up to $50 \%$ in China (17). Our results indicated that the rate of resistance to metronidazole and amoxicillin was very high in this region. Concerning the increasing rate of resistance to the antibiotics, which is currently used against $H$. pylori, it seems that finding effective alternative antimicrobial compounds is a necessity. Moreover, determining susceptibility and drug resistance patterns of this bacterium prior to initiation of therapy is advisable.

It has been demonstrated that lactobacilli and/or their metabolites are effective in preventing infections or delaying $H$. pylori colonization in gastric mucosa.
In a study on the antagonistic effect of $L$. casei on $H$. pylori and salmonella, it was revealed that $L$. casei inhibited the expression of $H$. pylori flagellin genes $\mathrm{A}$ and $\mathrm{B}$, which ultimately prevented from bacterial movement and resulted in morphology change to coccoid form (22). In the present study, most lactobacilli isolated from the milk of dromedary were related to $L$. plantarum, $L$. fermentum and L. casei.

In a study conducted in Morocco, $37.7 \%$ and $25.8 \%$ of strains isolated from the dromedary milk were lactobacilli and lactococci, respectively (23). We found that the $H$. pylori isolates resistant to all five antibiotics were susceptible to bacteriocins of lactobacilli isolated from camel milk. Similar to our study, Heidari et al. confirmed the antibacterial effect of bacteriocin produced by Lactobacillus isolates from diaries on 10 pathogenic bacteria using well diffusion assay (24). Another study has also confirmed the inhibitory effect of bacteriocin produced by lactobacilli isolates from milk on $H$. pylori (25). Khonafari et al. studied the production of Lactocins by probiotic strains in local yogurt samples. The results of this study showed the isolation of 21 strains of lactic acid bacteria. Production of antimicrobial combinations by strains in the logarithmic phase of their growth and their antimicrobial effects were also observed (26). Mojgani et al. confirmed the inhibitory properties of bacteriocin produced by $L$. acidophilus isolates from cheese samples in Karaj (Iran) against some pathogenic bacteria (27). In another study, leuconostocs, lactobacilli and enterococci were the most frequent lactic acid bacteria present in milk of Iranian dromedary (28). However, we found $L$. plantarum as the most frequent species. A study in 2015 investigated the in vitro antagonistic effects of $L$. casei on antibioticresistant $H$. pylori and confirmed the susceptibility of this pathogen to Lactobacillus (29).

Given the similarity with our findings, it should be noted that we isolated lactobacilli strains from camel milk and investigated the species resistant to multiple antibiotics.

\section{CONCLUSION}

Based on the results, it can be concluded that the rate of resistance to selective antimicrobial agents used for treatment of gastritis is increasing. Given the 
high resistance of $H$. pylori isolates to antibacterial agents and the inhibitory effects of lactic acid bacteria, the addition or presence of lactobacilli in fermented foods such as camel milk could have protective effects against infections that are caused by $H$. pylori. Thus, it is recommended to promote the consumption of such products to help improve public health.

\section{REFERENCES}

1. Shen L, Li J, Xu J, Pan H, Dai G, Qin S, Wang L, Wang J, et al. Bevacizumab plus capecitabine and cisplatin in Chinese patients with inoperable locally advanced or metastatic gastric or gastroesophageal junction cancer: randomized, double-blind, phase III study. Gastric Cancer. 2015; 18(1): 168-76. doi: 10.1007/s10120-014-0351-5.

2. Piard Jc, Desmazeaud M. Inhibiting factors produced by lactic acid bacteria Bacteriocins and other antibacterial substances. Le Lait, INRA Editions .1992; 72 (2): 113-42.

3. Dai YN, Yu WL, Zhu HT, Ding JX, Yu CH, Li YM. Is Helicobacter pylori infection associated with glycemic control in diabetics? World J Gastroenterol. 2015; 21(17): 5407-16. doi: 10.3748/wjg.v21.i17.5407.

4. Chen y, Blaser MJ. Association between gastric Helicobacter pylori colonization and glycated hemoglobin levels.J Infect Dis .2012; 205(8): 1195-1202.

5. Benmechernene Z, Fernández-No I, Quintela-Baluja M, Böhme K, Kihal M, Calo-Mata P, et al. Genomic and Proteomic Characterization of Bacteriocin-Producing Leuconostoc mesenteroides Strains Isolated from Raw Camel Milk in Two Southwest AlgerianArid Zones. BioMed Research International. 2014; 4: 1-9.

6. Benmechernene Z, Chentouf HF, Yahia B, Fatima G, Quintela-Baluja M, Calo-Mata P, et al. Technological Aptitude and Applications of Leuconostoc mesenteroides Bioactive Strains Isolated from Algerian Raw Camel Milk. BioMed Research International. 2013; 13: 1-14.

7. Hastings JW, Gibson PT, Chauhan R, Dykes GA, von Holy A. Similarity of bacteriocins from spoiled meat lactic acid bacteria. South African Journal of Science. 1996; 92(8): 376-80.

8 Mirdamadi S, Tangestani M. Screening and characterization of bacteriocins produced by some Strains of Lactobacillus spp isolated from Iranian Dairy Products.Food Health Journal.2012;1(3):55-70.

9. Clinical and Laboratory Institute (CLSI). Performance standards for antimicrobial susceptibility testing: M100-S17. Clinical and Laboratory Standards,26,1-182.Standards Institute (CLSI ). Clinical and Laboratory Standards. 2008.

10. Nishizawa T, Suzuki H. gastric carcinogenesis and underlying molecular mechanisms Helicobacter pylori and novel targeted therapy. Biomed Research International. 2014; 15:1-7. doi: 10.1155/2015/794378.

\section{ACKNOWLEDGMENTS}

This study has been supported by the Research Council of the Islamic Azad University of Gorgan, Iran. We would like to thank the gastroenterology centers in Tehran for supplying the biopsy specimens.

\section{CONFLICT OF INTEREST}

The authors declare no conflict of interest.

11. Heep M, Kist M, Strobel S, Beck D, Lehn N. Secondary resistance among 554 isolates of Helicobacter pylori

after failure of therapy. Eur J Clin Microbiol Infect Dis. 2000; 19(7): 538-42.

12. Cabrita J, Oleastro M, Matos R, Manhente A. Features and trends in Helicobacter pylori antibiotic resistace in Lisbon Portugal (1990-9). J Antimicrobial Chemotherapy. 2000; 46(6): 1029-31.

13. Picot S, Sapin G, Michault A, FaulquesB. Antibiotic resistance of Helicobacter pylori

in Reunion Island: therapeutic consequences. Bull Soc Pathol Exot. 2002; 95(2): 66-70.

14. Toro C, Garcia SJ. Prevalence of primary Helicobacter pylori resistance to eight antimicrobial agents in a hospital in Madrid. Rev Esp Quimioter. 2001; 14(2): 172-76.

15. Eltahawy AT. Prevalence of primary Helicobacter pylori resistance to several antimicrobials ina Saudi Teaching Hospital. Med Princ Pract. 2002; 11(2): 65-68.

16. Kim JJ, Reddy R, Lee M, Kim JG. Analysisof metronidazole, clarithromycin and tetracyclineresistance of Helicobacter pylori from Korea. J Antimicrob Chemother. 2001; 47(4): 459-61.

17. Wu H, Shi XD, Wang HT, Lin jx. Resistanceof Helicobacter pylori to metronidazole,

tetracycline and amoxicillin. J Antimicrob Chemother. 2000; 46(1): 121-23.

18. Mohammadi M, Doroud D, Mohajerani N, Massarrat S. Helicobacter pylori Antibiotic

Resistance in Iran. World J Gastroenterol. 2000; 11(38): 6009-13. doi: 10.3748/wjg.v11.i38.6009

19. Toracchio S, Marzio L. Primary and secondaryantibiotic resistance of Helicobacter pylori strains isolated in central Italy during theyears 19982002. Dig Liver Dis. 2003; 35(8): 541-45.

20. Selgrad M, Malfertheiner P. New strategiesfor Helicobacter pylori eradication. Curr Opin Pharmacol. 2008; 8(5):593-7. doi: 10.1016/j.coph.2008.04.010.

21. Falsafi T, Mobasheri F, Nariman F, Najafi M. Susceptibilities to Different Antibiotics of Helicobacter pylori Strains Isolated fromPatients at the Pediatric Medical Center of Tehran, Iran. JCM. 2004; 42(1): $387-$ 89. 
22. Le Moal VL, Fayol-Messaoudi D, Servin AL. Compound(s) secreted by Lactobacillus casei strain Shirota YIT9029 irreversibly and reversibly impair the swimming motility of Helicobacter pylori and Salmonella enterica serovar Typhimurium, Respectively.

Microbiology. 2013;159(9):1956-71. doi: 10.1099/mic.0.067678-0.

23. Khedid K, Faid M, Mokhtari A, Soulaymani A, Zinedine A. Characterization of lactic acid bacteria isolated from the one humped camel milk produced in Morocco. Microbiol Res. 2009; 164(1): 81-91.

24. Heydari Z, Ghaemi N,Faezi Ghasemi M. Evaluation of In situ Activity of Bacteriocin Produced by Lactic Acid Bacteria Isolated from Dairy Products.Journal of Biology Science.2008;1(3):13-22.

25.Hosseini doust R,Mohabati Mobarez A, Amini M. Inhibitory effects of probiotics on $\mathrm{H}$. pylori by co-culture method. Scientific Journal of Kurdistan University of Medical Science.2008;13(3):62-69.

26. Khonafari A, Esmaeilzadeh M, Akhavan Sepahi A.Potential Ability of Probiotics Isolated from Iranian Local Yogurts of Produce lactacins. Journal of Nutrition Sciences \& Food Technology.2009; 4(1): 67-78.
27.Mojgani N, Esmail Khanian S, Ameli M, Yousefi M. Detection and characterization of a bacteriocin (RN78 )produced by Lactobacillus acidophilus strain isolated from a cheese sample. $\mathrm{J}$ Pajouhesh Sazandegi. 2006;19(2):36-42.

28. Enany S, Abdalla S. In vitro antagonistic activity of Lactobacillus casei against Helicobacter pylori. Braz J Microbiol. 2015; 46(4): 1201-6. doi: 10.1590/S1517838246420140675.

29. Davati N, Tabatabaee Yazdi F, Zibaee S, Shahidiand F, Edalatian MR. Study of Lactic Acid Bacteria Community from Raw Milk of Iranian One Humped Camel and Evaluation of Their Probiotic Properties. Jundishapur Journal ofMicrobiology. 2015; 8(5):1-6. DOI: $10.5812 /$ jjm.8(5)2015.16750.

30. Naghshvar F, Tirgar Fakheri H, Torabizadeh Zh, Emadian O, Maleki E, Zare A. Antibiotic resistance of Helicobacter pylori isolated from patients admitted to Imam Hospital, Sari, Iran, 2002-2003. J Mazand Univ MedSci. 2004; 15(48): 99-104. 